\title{
Enriching the HSN With Individual Causes of Death. A Database for a Life-Course Analysis of Victims and Survivors
}

By Tim Riswick

To cite this article: Riswick, T. (2021). Enriching the HSN With Individual Causes of Death. A Database for a Life-Course Analysis of Victims and Survivors. Historical Life Course Studies, 10, 34-40. https://doi.org/10.51964/hlcs9564

\section{HISTORICAL LIFE COURSE STUDIES}

Not Like Everybody Else.

Essays in Honor of Kees Mandemakers

VOLUME 10, SPECIAL ISSUE 3

2021

GUEST EDITORS

Hilde Bras

Jan Kok

Richard L. Zijdeman 


\section{HISTORICAL LIFE COURSE STUDIES}

Historical Life Course Studies is the electronic journal of the European Historical Population Samples Network (EHPSNet). The journal is the primary publishing outlet for research involved in the conversion of existing European and nonEuropean large historical demographic databases into a common format, the Intermediate Data Structure, and for studies based on these databases. The journal publishes both methodological and substantive research articles.

\section{Methodological Articles}

This section includes methodological articles that describe all forms of data handling involving large historical databases, including extensive descriptions of new or existing databases, syntax, algorithms and extraction programs. Authors are encouraged to share their syntaxes, applications and other forms of software presented in their article, if pertinent, on the openjournals website.

\section{Research articles}

This section includes substantive articles reporting the results of comparative longitudinal studies that are demographic and historical in nature, and that are based on micro-data from large historical databases.

Historical Life Course Studies is a no-fee double-blind, peer-reviewed open-access journal supported by the European Science Foundation (ESF, http://www.esf.org), the Scientific Research Network of Historical Demography (FWO Flanders, http://www.historicaldemography.be) and the International Institute of Social History Amsterdam (IISH, http://socialhistory.org/). Manuscripts are reviewed by the editors, members of the editorial and scientific boards, and by external reviewers. All journal content is freely available on the internet at https://openjournals.nl/index.php/hlcs.

\section{Co-Editors-In-Chief:}

Paul Puschmann (Radboud University) \& Luciana Quaranta (Lund University)

hislives@kuleuven.be

The European Science Foundation (ESF) provides a platform for its Member Organisations to advance science and explore new directions for research at the European level. Established in 1974 as an independent non-governmental organisation, the ESF currently serves 78 Member Organisations across 30 countries. EHPS-Net is an ESF Research Networking Programme.

The European Historical Population Samples Network (EHPS-net) brings together scholars to create a common format for databases containing non-aggregated information on persons, families and households. The aim is to form an integrated and joint interface between many European and non-European databases to stimulate comparative research on the micro-level.

Visit: http://www.ehps-net.eu.
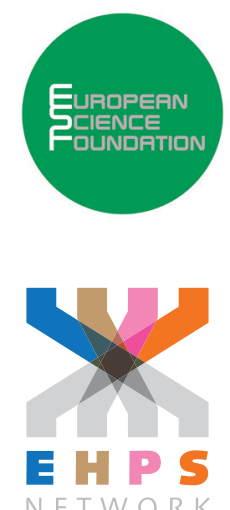


\title{
Enriching the HSN With Individual Causes of Death
}

\section{A Database For a Life-Course Analysis of Victims and Survivors}

\author{
Tim Riswick \\ Radboud University Nijmegen
}

\section{ABSTRACT}

The focus of this article is on how a newly created database on causes of death in Amsterdam (18541940) may offer innovative insights by combining it with the available information from the Historical Sample of the Netherlands (HSN). By doing so, it illustrates how future research can help to provide new perspectives on ongoing debates on historical and contemporary infectious diseases by combining information from several historical sources and databases.

Keywords: Causes of death, Infectious diseases, Mortality risks, Amsterdam

e-ISSN: $\quad 2352-6343$

DOI article: $\quad$ https://doi.org/10.51964/hlcs9564

The article can be downloaded from here.

This open-access work is licensed under a Creative Commons Attribution 4.0 International License, which permits use, reproduction \& distribution in any medium for non-commercial purposes, provided the original author(s) and source are given credit. See http://creativecommons.org/licenses/. 


\section{INTRODUCTION}

During the last decades of the 20th century the medical world was full of optimism that infectious disease threats were gone. Recently, however, infectious microbes have provided reminders that the microbial world is fully alive and still can have an enormous influence on our modern society (Hardt, 2016, pp. iv-xxiv). The recent COVID-19 crisis is, however, just one demonstration of the fact that the history of infectious diseases in western societies is far from over. Moreover, the current crisis makes it clear that it is more important than ever to increase our understanding of who is affected by infectious diseases and why. Historical research may offer important new insights into the impact of infectious diseases by studying who was affected by infectious diseases in pre-modern societies, why these people were affected, and if this changed over time. It may increase our understanding of how deaths due to infectious diseases, which were numerous in the past, impacted individuals, families, communities and society at large. In this brief article, part of the special issue honouring the work of Kees Mandemakers, the focus will be on how a newly created database on causes of death in Amsterdam may offer innovative insights. Moreover, by combining it with the available information from the Historical Sample of the Netherlands (HSN), it illustrates how future research can help to provide new perspectives on ongoing debates on historical and contemporary infectious diseases. ${ }^{1}$

\section{DEBATING THE DETERMINANTS OF MORTALITY}

To explain differences in all-cause and cause-specific mortality risks, socioeconomic determinants are considered to be the most important factors. They define the kind and amount of resources available for individuals to influence their exposure to proximate determinants of mortality. These proximate determinants are often grouped into five categories: maternal factors (age, parity, birth interval), environmental contamination (air, food, water, soil, insects), nutrient deficiency (calories, proteins, micronutrients), injury, and personal illness control. Together they serve as indicators to measure what causes people to be healthy or to become sick, and, if nothing is done, what causes people to die (Mosley \& Chen, 1984). It clarifies the many factors involved in infant and child mortality and makes it understandable how seemingly disparate measures can have an influence on each other and on health outcomes. In addition, the resources available to individuals are determined not only by his/her own choices, but also by the constraints imposed by household or state actors. Individual health is therefore also dependent on the household and societal context (Riswick, 2020, pp. 24-35).

The group of socioeconomic and proximate determinants is large, and for most of them it is difficult to construct reliable indicators. Many studies have therefore focused on specific determinants like improvement in sanitation, public hygiene, economic development, cultural norms of religious groups and so on. Moreover, most of the previous research has used highly aggregated data. This comes with the fundamental drawback that investigating which determinants affected the individual likelihood of dying from historical infectious diseases, and for what reasons, is not possible. The result is that it remains unclear how exactly individual and family characteristics impacted upon the risk of death from a specific infectious disease, and how these relationships may have changed over time. A solution, however, is to study all-cause and cause-specific mortality and use individual level data instead. This makes it possible to examine individual, household, and neighbourhood level indicators of both socioeconomic and proximate determinants of health.

1 The described research is part of the NWO project 'Lifting the burden of disease. The modernisation of health in the Netherlands: Amsterdam 1854-1940' headed by Angélique Janssens and Jacco Wallinga; grant number: 406.18.HW.011. 


\section{SAMPLE OF THE NETHERLANDS}

Information on individual causes of death has recently become available due to the efforts of digitising the Amsterdam causes-of-death registers through the Radboud Group Citizen Science for the History of Health. ${ }^{2}$ The registers are unique as there are only a few known places where this kind of registration has survived, but none in cities as large as Amsterdam and for such a long time span. They cover roughly the period between 1854 and 1940, although some years are missing. Although the information in the registers changed over time, information is available on the date of death, place of death, address of the deceased, sex, marital status, age at death, occupation and cause of death. The first line in Figure 1 shows, for example, that on 9 May 1885 a man died at age 39 from nephritis, chronica uraemia and convulsiones. He lived in house number 19, in the Amstel, and was a jeweller. The source, however, does not only offer information about the inhabitants of Amsterdam, but also about people who died while passing through. This often results in less detailed information, as is illustrated by the 12-weekold boy who died on 24 June 1885 from atrophia on a ship at Kloveniersburgwal. Yet, sometimes additional information was written down when the death of the person was more remarkable. For instance, the death of someone who was part of a group of travelling Zulu performers from Africa was also recorded. While the whole group were staying at the Warmoesstraat 128 , he died from phthisis pulmonum in the hospital. These examples demonstrate how the causes of death registers not only offer insight into how people died, but also on how they lived. Moreover, they make it possible to contextualise death and disease at the individual level.

Figure $1 \quad$ A page from the Amsterdam causes of death registers; number: BSDA00063000009

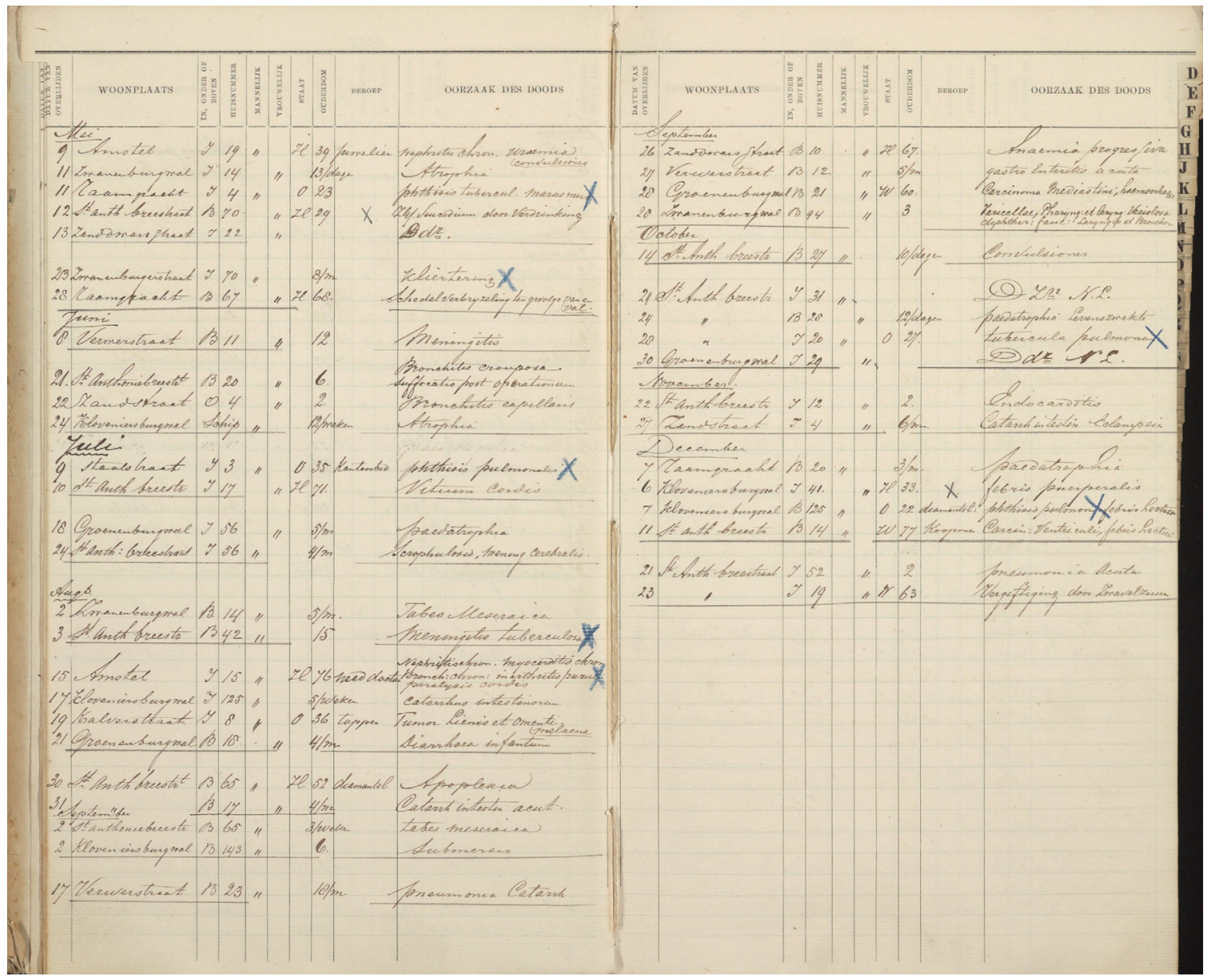

2 See for more information www.ru.nl/rich/our-research/research-groups/radboud-group-for-historicaldemography-and-family/current-research-projects/rg-citizen-science-history-health/. 
An additional advantage is that the causes of death are not yet aggregated at a higher level into disease classifications set up by 19th-century health practitioners. For aggregated numbers it is much more difficult to reclassify cause of death categories because the nomenclature is predefined. In general the first classification system was based on British mortality statistics and its disease classification system. Yet, it also changed several times in the course of the 19th and early 20th centuries. For instance, in the cause of death statistics of 1866, the classification was mainly based on the most prevalent contagious diseases, while a year later a new classification was introduced that divided 55 separate causes of death into 11 different categories. In 1875, the nomenclature was again transformed into 35 different categories of diseases (van den Boomen \& Ekamper, 2015). Only with the creation of the International Statistical Classification of Diseases and Related Health Problems (ICD) in 1893 did a more standardised and internationally comparable nomenclature become available. These changes over time also make it difficult to reclassify disease groups, and make it impossible to do so on the individual level. Not being able to do this has been a huge limitation when using aggregate data.

For the individual causes of death from Amsterdam it is possible to recode them according to the specifically designed historical version of the current ICD, the ICD10h, which is developed by the SHiPnetwork (Janssens \& Walhout, 2018). As a result, the causes of death of the jeweller mentioned above can be coded as N03.900 (chronic inflammation of the kidney), N18.500 (chronic kidney disease), and R56.800 (convulsions). The boy who died at a ship can be coded as R64.003 (atrophy) and the Zulu man as A16.903 (respiratory tuberculosis unspecified). This greatly increases the possibilities for research because it becomes feasible to create the separate disease classifications needed for specific research questions.

As mentioned before, how exactly individual and family characteristics impacted upon the risk of dying from a specific infectious disease, and how these relationships may have changed over time, is still unclear. Answering these questions is, however, not possible with the data from the individual cause of death registers alone because they lack the required information. Only by combining them with the civil registry does it become possible to attain information on the population at risk, household characteristics (such as the composition or size of the household), and individual characteristics (such as religion, occupation of the father, and position in the household). This is key to the study of the importance of the aforementioned socioeconomic and proximate determinants for all-cause and specific-cause mortality risks. A first way of obtaining the information needed would be to link the persons for whom we have a cause of death to their own and their family's birth, marriage and death certificates. A difficulty, however, is that no name of the deceased person was written down. Identifying the deceased is therefore only possible by looking up the death certificate of the person that matches the information in the causes of death registers on the date of death, age of death, sex and address of the deceased. Walhout (2019) for example has already successfully used this approach. Yet, while for many regions in the Netherlands information from birth, marriage and death certificates is already digitally available in the LINKS-database, this is not the case for the birth and death certificates from Amsterdam.

A second way of studying individual and family characteristics is to use the information that is already available in the HSN. The HSN is not only based on the birth, marriage and death certificates, but also on population registers. The advantage of population registers is that information was not recorded on a single occasion, but was updated every time there was a change in the household. Moreover, they also contain information about religion and household composition. Still, the most important feature of the HSN data is that it presents the research person in constantly changing stages of the life course for the period 1850-1940 (Mandemakers, 2006). In the HSN Life Courses Release 2010.01 there are 13,795 persons who are born in Amsterdam during the period 1854-1909. In total 2,693 of these persons died in Amsterdam before their tenth birthday. These persons can be linked when the date of death, age, sex and last known address in the HSN matches the information in the Amsterdam cause of death database. For the period 1853-1892 there are 718 out of the 1419 persons in the HSN who died in Amsterdam and who could automatically be linked to their cause of death. ${ }^{3}$

3 At this moment the Amsterdam cause of death data for the period beyond 1892 are not yet available for analysis due to the ongoing process of data cleaning and data coding. In addition, it is possible to link more causes of death to HSN persons who died in Amsterdam when relaxing the matching criteria. For his article, however, I decided to only use the cases that could be linked on all available information. 
Table $1 \quad$ Frequencies of the cause-of-death categories in the Amsterdam causes of death registers database and the Historical Sample of the Netherlands (excluding still births) until age 10

\begin{tabular}{lrrrr}
\hline ICD10h & \multicolumn{2}{c}{ Amsterdam } & \multicolumn{2}{c}{ HSN } \\
disease chapters & N & \multicolumn{1}{c}{$\%$} & \multicolumn{1}{c}{ N } & \multicolumn{1}{c}{$\%$} \\
\hline Certain infectious and parasitic diseases (A \& B) & 42273 & 30.5 & 237 & 32.9 \\
Neoplasms and diseases of the blood (C \& D) & 522 & 0.4 & 6 & 0.8 \\
Endocrine, nutritional and metabolic diseases (E) & 965 & 0.7 & 6 & 0.8 \\
Diseases of the nervous system (G) & 9477 & 6.8 & 32 & 4.4 \\
Diseases of the circulatory system (I) & 639 & 0.5 & 8 & 1.1 \\
Diseases of the respiratory system (J) & 25682 & 18.5 & 160 & 22.2 \\
Diseases of the digestive system (K) & 3582 & 2.6 & 24 & 3.3 \\
Diseases of the skin and subcutaneous tissue (L) & 261 & 0.2 & 1 & 0.1 \\
Diseases of the musculoskeletal system and connective tissue (M) & 421 & 0.3 & 2 & 0.3 \\
Diseases of the genito-urinary system (N) & 632 & 0.5 & 8 & 1.1 \\
Certain conditions originating in the perinatal period (P) & 16426 & 11.9 & 81 & 11.2 \\
Congenital malformations, deformations and chromosomal & 340 & 0.2 & 2 & 0.3 \\
abnormalities (Q) & & & & \\
Symptoms, signs and abnormal clinical and laboratory findings, & 36116 & 26.1 & 146 & 20.3 \\
not elsewhere classified (R) & & & & \\
Injury, poisoning and certain other consequences of external & 672 & 0.5 & 2 & 0.3 \\
causes (S \& T) & & & & \\
External causes of morbidity (V \& W \& X \& Y) & 327 & 0.2 & 3 & 0.4 \\
\hline
\end{tabular}

Figure 2 Kaplan-Meier survival curve of all-cause mortality of the selected HSN persons by gender (1854-1892)

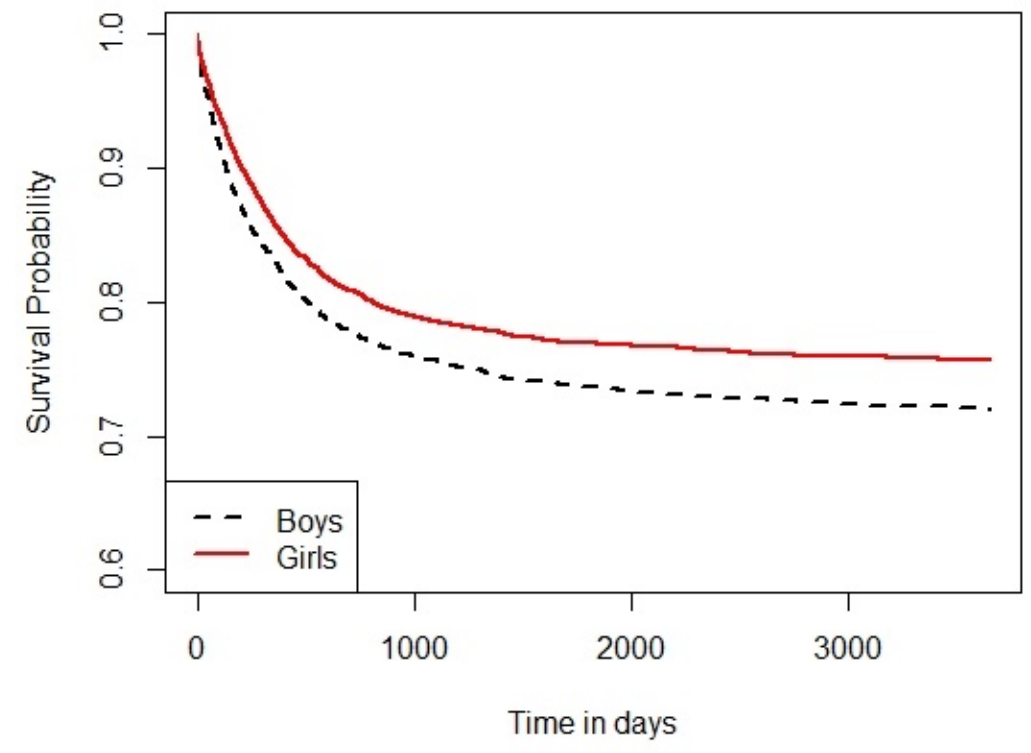


Table 1 shows the number of people who died before age 10 in a specific disease classification of the ICD10h in the Amsterdam database in the period 1854-1892, and the ones who could be matched in the HSN during the same period. The A and B (infectious diseases and parasitic diseases), R (symptoms and signs not elsewhere classified) and $J$ (diseases of the respiratory system) classifications represent the largest groups of causes of death. The $P$ (conditions originating in the perinatal period) and $G$ (diseases of the nervous system) classifications are smaller, but still account for more than $5 \%$. The percentage of children who died in these categories is as we would expect from previous research. The Kaplan-Meier survival curve of all-cause mortality of the selected HSN persons in Figure 2 demonstrates that the same is true regarding the mortality risks: $30 \%$ of the boys died before age 10 , and $25 \%$ of the girls died before age 10 during the period 1854-1892 (Jansen \& de Meere, 1982). It therefore demonstrates that in general the HSN should be sufficiently comparable with the general population to say something about how individual and family characteristics impacted upon the risk of dying from specific diseases.

\section{FUTURE RESEARCH OPPORTUNITIES}

Kees Mandemakers has spent his whole career advocating that by combining information from different sources and reliable datasets historians can generate new insights into how historical life courses of our predecessors evolved. The specific example chosen in this article illustrates how combining digitised information from several sources provides an opportunity to study who was affected by infectious diseases, why these people were affected, and if this changed over time. In turn, this may also provide generalisable insights into the impact of current and future infectious diseases.

With regard to studying individual and family characterises with the Amsterdam cause of death database, three further directions for future research into infectious diseases will be followed. Firstly, to solve a part of the problem of there being no information from birth and death certificates for Amsterdam, volunteers working in the Radboud Group Citizen Science for the History of Health are transcribing and entering all birth certificates of a selection of years, and the death certificates of those who were born in these selected years and died as an infant (0-12 months) or child (1-5 years). This makes it possible to use information for a larger number of people, to know the population at risk, and to take the influence of individual and family characteristics on the risks of dying from specific infectious diseases into account. Secondly, to be able to incorporate the environmental context, sources describing possible environmental contamination and health services will be considered as well. For example, information on sanitation (sewage and piped water), where doctors and midwives lived, and weather conditions (temperature and humidity) will be included. Lastly, knowledge on disease and infectious microbes will be integrated as the epidemiological side of population change should not be excluded. This will be possible by including factors for the infectivity and susceptibility of specific diseases. By taking these steps, we expect an important breakthrough in the current academic debate on the determinants of the decline in mortality, one that will reveal the progress already made against infectious diseases before the start of the mass vaccination programme.

\section{REFERENCES}

Hardt, M. D. (2016). History of infectious disease pandemics in urban societies. Lanham, MD: Lexington Books.

Jansen, P. C., \& de Meere, J. M. M. (1982). Het sterftepatroon in Amsterdam 1774-1930. Een analyse van de doodsoorzaken. Tijdschrift voor Sociale Geschiedenis, 8, 180-223.

Janssens, A., \& Walhout, E. (2018). Gateways of disease? Do port cities have different cause-of-death patterns compared to other cities, the case of the Netherlands, 1875-1899. In P. Puschmann and T. Riswick (Eds.), Building bridges. Scholars, history and historical demography. A Festschrift in honor of professor Theo Engelen (pp. 332-361). Nijmegen: Valkhof Pers. Retrieved from https:// lirias.kuleuven.be/retrieve/518565 
Mandemakers, K. (2006). Building life course datasets from population registry by the historical sample of the Netherlands (HSN). History and Computing 14(1-2), 87-107. doi: 10.3366/ hac.2002.14.1-2.87

Mosley, W. H., \& Chen, L. C. (1984). An analytical framework for the study of child survival in developing countries. Bulletin of the World Health Organization, 81(2), 140-145. Retrieved from http://pubmed.ncbi.nlm.nih.gov/12756980/

Riswick, T. (2020). Between rivalry and support: The impact of sibling size and composition on infant and child mortality in the Netherlands (1863-1910) and Taiwan (1906-1945) (Doctoral dissertation, Radboud University Nijmegen). Enschede: Ipskamp Printing.

van den Boomen N., \& Ekamper, P. (2015). Denied their 'natural nourishment': Religion, causes of death and infant mortality in the Netherlands, 1875-1899. The History of the Family, 20(3), 391-419. doi: 10.1080/1081602X.2015.1022199

Walhout, E. C. (2019). An Infants' Graveyard? Region, religion, and infant mortality in North Brabant, 1840-1940 (Doctoral dissertation, Tilburg University). Retrieved from https:// research.tilburguniversity.edu/en/publications/an-infants-graveyard-region-religion-and-infantmortality-in-nort 